\title{
Girândolas: Escola e Literatura nas margens ribeirinhas de Abaetetuba.
}

\author{
Jones da Silva GOMES ${ }^{1}$ \\ Universidade Federal do Pará - UFPA \\ jones@ufpa.br /jonesgom@yahoo.com.br
}

Resumo: Em Girândolas sugere-se a imagem de uma escola como evento histórico seminal para uma comunidade ribeirinha. O romance é narrado pelas memórias de Tobias- fazedor de brinquedos de miriti e Maria- a benzedeira, entre outros personagens D. Constança a professora era considerada um divisor de águas. Nas leituras que os discentes de educação do campo UFPA/ fizeram do livro, foi possível aproximar a literatura do saber local, as experiências dos alunos e seu despertar para o oficio de ensinar. Por isso, reconhecemos que a escola descrita pelo autor oferece uma narrativa para se pensar o campo a partir das dores e esperanças de seus moradores. Assim, ficção e realidade afirmam-se nas veredas da memória que reivindica o direito de estudar, os sonhos comuns e a liberdade.

Palavras Chave: Girândolas, Escola do Campo, Literatura, Comunidade $e$ Narradores.

\begin{abstract}
In Girândolas is suggested the image of a school as a seminal historic event for a riverside community. The novel is narrated by Tobias- doer memories of Miriti toys and Maria- the healer, among other characters Constança the teacher was considered a watershed. In readings the field of education students UFPA / did the book, it was possible to approach the literature of local knowledge, the experiences of the students and their awakening to the office of teaching. Therefore, we recognize that the school described by the author provides a narrative to think about the field from the pains and hopes of its residents. Thus, fiction and reality say is the memory of the paths that claims the right to study, common dreams and freedom.
\end{abstract}

Keywords: Girândolas, Field School, Literature, Community and Storytellers.

\footnotetext{
${ }^{1}$ Doutor em Ciências Sociais (PPGCS-UFPA) e Professor do curso de Licenciatura em Educação do Campo/UFPACampus Abaetetuba.
} 


\section{1- Introdução:}

A escola do campo proposta por Maciste ${ }^{2}$ mergulha na memória de uma comunidade e se avizinha das margens, tema recorrente na literatura. Guimarães Rosa ${ }^{3}$, por exemplo, descreve Riobaldo confidenciando a Quelemém de Gois sua inserção precária no mundo das letras: "Tive Mestre, Mestre Lucas, no curralinho, decorei gramatica, as operações, regra de três, até geografia". Tempos depois o próprio Riobaldo terá suas breves experiências como professor do ensino rural. Ora, a despeito destas imagens que em comum configuram um Brasil com grandes problemas educacionais nas áreas rurais, nos perguntamos como a chegada de uma escola nas ilhas de Abaetetuba coincide com a esperança de uma vida melhor para a comunidade? No livro Girândolas de Daniel Leite esta questão toma uma forma ética antes que estética. Tobias é o narrador que vivencia a construção de um sonho (uma escola) ao testemunhar a chegada da professora- Dona Constança- como um divisor de águas que inicia um tempo-escola.

Por outro lado, a escola expõe os sacrifícios de ribeirinhos, pescadores, extrativistas, artesãos, agricultores, navegadores, quilombolas, indígenas. Ora, ela é resultado das limitações de ordem físicos, sociais e culturais, como expiação de uma meta que sempre está por fazer-se, pressupõem também as travessias rumo ao gesto do educar-se, que para o autor seria como: "Um lugar que ensinasse a vida e todas as ciências do viver". (LEITE, 2013). A exemplo das comunidades que nos mutirões constroem suas escolas, podemos pensar nos estudantes que hoje chegam na universidade e se deparam com a dor e a esperança de cursar uma licenciatura, num trajeto marcado por encontros e desencontros da experiência acadêmica, que, todavia, ainda permite um compartilhar juntos a tarefa de educar-se: "Todas as gentes que moravam ao longo das sete comunidades do nosso rio ajudaram no trabalho de levantar a escola no meio das águas". (Idem)

Ora, os estudantes dos muitos rios lidam cotidianamente com o modelo educacional urbano, que chega hoje na matriz imagética dos livros didáticos, parâmetros curriculares,

\footnotetext{
${ }^{2}$ Maciste Costa, ilustrador do livro Girandolas em sua 2a Edição.

${ }^{3}$ ROSA, Guimarães. Grandes Sertões: Veredas. Rio de Janeiro, Nova Fronteira, 2006.

MARGENS - Revista Interdisciplinar

Versão Digital - ISSN: 1982-5374 
mídia, celulares, precariedade de espaços, sem contar na dificuldade de chegar a escola, permanecer e desenvolver um afeto positivo por ela. Mas, como o próprio romance descreve, a escola é ainda o lugar da reunião, da sociabilidade e da partilha do conhecimento. Por isso, tentamos escutar os ecos que reverberam em desafios aos direitos das populações do campo na Amazônia, sobretudo, o direito de estudar. Por isso, percorri os sinais deixados pelo romance "Girândolas" de Daniel Leite, que entre outros temas trata da vinda de uma escola para uma comunidade das ilhas; adentrei a Literatura que me remeteu as margens da oralidade ribeirinha; identificando nela narrativas semelhantes aos dos alunos de Licenciatura (futuros professores de educação do campo) UFPA/Campus do Baixo Tocantins-AbaetetubaPA.

A ideia foi lançar um olhar sobre o "Campo" em diálogo com a Literatura e apresentar algumas questões que achamos nortear os muitos desafios postos à Universidade, Movimentos Sociais, Gestores, Professores e alunos das escolas do campo. E, no momento em que se comemoram os 10 anos da revista "Margens" sinto-me jovialmente envolvido na tarefa de revisita-la, agora como autor, remando para as margens da qual espreitamos uma escola, escutamos suas histórias e atravessamos para o outro lado. Por isso, devo esclarecer que não sou especialista em assuntos educacionais, muito menos um crítico literário ou estudioso de literatura. Mas, é certo dizer que minhas pesquisas, envolvidas que estão pelas questões do Campo na Amazônia- refletem a tentativa de aproximação das muitas áreas dos saberes como a Literatura, Educação e a Sociedade com a finalidade de uma reflexão perpassada pelos os temas do imaginário ribeirinho em seu conteúdo simbólico, estético e pedagógico. O percurso do reconhecimento ${ }^{4}$ remete-nos para o olhar a escola do campo, como se desse gesto fossemos capazes de conhecer um pouco mais daquelas margens, naquilo que elas têm de trágico e belo, de positivo e negativo, na nudez de suas matas e na abundância de seus rios. O desafio de educar em meio ao desencantamento da educação é uma questão colocada pela imagem da escola do campo, por isso, lidamos com as narrativas das comunidades que fazem do educar-se- um gesto partilhado e esperançoso.

${ }^{4}$ RICOEUR, Paul. Percurso do Reconhecimento. São Paulo: Edições Loyola, 2006.

MARGENS - Revista Interdisciplinar Versão Digital - ISSN: 1982-5374
10 anos de Margens - Dossiê: Olhares para o campo... VOL.10. N. 15. Dez 2016. (p. 115-132) 
O livro Girandolas considerado por seu autor e tempo narrativo, traz a imagem da escola como fato exemplar para as muitas comunidades ribeirinhas; a leitura e a interpretação do livro feita pelos discentes do curso de Licenciatura em Educação do Campo/UFPACampus Abaetetuba, na disciplina Linguagem e Comunicação do Campo, ajudou-me a perceber o quanto a literatura tem a contribuir na tentativa de um reconhecimento do saber local, por isso, nesta travessia o livro e a realidade do aluno se encontram em auxilio da reflexão e ação coletiva das questões relacionadas ao ensino das escolas do campo. Por fim, analisaremos algumas narrativas recolhidas em viagem de Tempo-Comunidade/na disciplina prática pedagógica ${ }^{5}$ com os alunos acima citados, na escola São João Batista no rio Campopema $^{6}$, considerando os fatos que tipificam relações e sentimentos atrelados a escola. Acreditamos que a vivencia pedagógica proporcionada pelo curso de licenciatura em Educação do campo, oferece um contex to bem peculiar para uma proposta interdisciplinar que envolva a literatura, as ciências humanas e os saberes locais. Foi com este intuito que pensei utilizar o livro Girandolas em minhas reflexões, ou seja, observando as ações formativas que apresentaram-se nos processos mediadores e reflexivos oriundos de uma comunidade da aula, pela a experiência de olhar a escola das margens da Amazônia Abaetetubense.

\section{2- Girândolas: A experiência das muitas margens ribeirinhas}

Girândolas é uma cruz de braço duplo em Miriti onde os artesões de Abaetetuba fincam os seus brinquedos (sonhos) para vender no Círio de Nazaré e Conceição, a expressão também remete aos círculos ou travessões em que fogueteiros arremessam os seus projeteis luminosos nos céus das festividades de santos das cidades ribeirinhas do Brasil. Girandolas é também o título de um romance poético escrito por Daniel Leite (2009) e reeditado em (2013). O romance é uma narrativa oral, fragmentos da memória de Tobias- o artesão, na sua busca por Maria- a benzedeira: “E tu já estavas prometida para a palavra, um mundo teu

\footnotetext{
5 A Prática Pedagógica trata-se de uma disciplina que tem uma finalidade atrelada à docência e outra a pesquisa (tempo-comunidade).

${ }^{6} \mathrm{O}$ referido Tempo- Comunidade deu-se no dia 22 de Fevereiro de 2016 na comunidade do rio Campopema, município de Abaetetuba-PA.
}

MARGENS - Revista Interdisciplinar

Versão Digital - ISSN: 1982-5374
10 anos de Margens - Dossiê: Olhares para o campo... VOL.10. N. 15. Dez 2016. (p. 115-132) 
de mulher, uma ternura, um fazer de miriti, os segredos de um verbo amar. Eras tu o que a minha ternura foi capaz de desenhar" (LEITE, 2009, p. 7). E a ela que tudo se endereça, numa esboça manifestação de um tempo psicológico acrescido de um discurso direto.

A trama ocorre numa das muitas ilhas sem nome que o autor identifica por ilha Sirituba, localizada a margem esquerda do rio Maratauíra ${ }^{7}$. O narrador relembra a infância, os rios, uma vida de miriti. Daniel Leite faz sua viagem imaginária as ilhas de Abaetetuba pelo voltar de Tobias à comunidade dos setes rios, seus encontros e desencontros, por entre as frestas dos Miritizais um afeto por Maria. A escola, o trapiche, o contador, a parteira, os brinquedos são tantas outras imagens que se materializam neste local e narram um estar junto. O simbólico na atividade literária está embebido do mito e repete-se na margem da linguagem pelos narradores que falam em Tobias. Convém frisar que a narrativa faz o uso estético do brinquedo de miriti, aqui e ali "identificamos um mobile de miriti" e este perpassa toda obra numa memoria da infância, faz-se lembrar seu profundo enraizamento na vida ribeirinha. Por sua vez, as girândolas que carregam os sonhos dos artesãos é um recurso metafórico que vem em auxilio da ideia do reconhecimento cultural.

O brinquedo lembra uma Abaetetuba da singularidade dos modos de vida que perpassam a cultura em sua expressão local. Para o antropólogo americano Clifordd Geertz ${ }^{8}$, o saber local em sua relação com o (Direito) o simbólico nos permite compreender o fenômeno cultural pelo local nas teias de significação pela imagem literária dos contos, romances, poemas, que são pontes de reconhecimento do outro concluiu-se, que: "Assim como a navegação, a jardinagem e a poesia, o direito e a etnografia também são artesanatos locais: funcionam à luz do saber local". (Geertz, p.249). Ora, o local visto sobre o olhar das tradições orais- envolvido que está com a natureza e suas artes de fazer ${ }^{9}$, vem ser o sumo da literatura na Amazônia. Credito se dê a estes fatos, quando lemos os relatos dos Viajantes e Padres Jesuítas, além dos romancistas: Inglês de Souza e Euclides da Cunha e as narrativas de Dalcídio Jurandir (2008) com seu "Marajó", síntese do ciclo do extremo norte, referência

7 Maratauíra: Pequeno braço de rio caudaloso separado por uma série de ilhas.

${ }^{8}$ GEERTZ . O saber local. Novos ensaios em Antropologia Interpretativa. Petropolis, Ed. Vozes, 1997.

${ }^{9}$ CERTEAU, Michel. A invenção do Cotidiano: Artes de fazer. Petrópolis: Vozes, 2003.

MARGENS - Revista Interdisciplinar Versão Digital - ISSN: 1982-5374
10 anos de Margens - Dossiê: Olhares para o campo... VOL.10. N. 15. Dez 2016. (p. 115-132) 
para a literatura nacional. O Marajó e seus campos de Cachoeira narrado por Alfredo é tão universal como o solo russo cobiçado pelo camponês Pakhóm criado por Tolstoi ${ }^{10}$ no conto “De quanta terra precisa o homem”. Girandolas, por sua vez, expressa está experiência de localização do tema, este momento em que a literatura tem um cheiro de terra e derrama a experiência na fala do velho Tibúrcio- contador de histórias dos trapiches e margens dos rios.

Em Benjamin ${ }^{11}$, para o qual o narrador é portador da experiência, já que possui laços com a comunidade, como o velho Tibúrcio geralmente (o lavrador, o viajante e o artesão) são aqueles que partilham a experiência e a tradição pela oralidade, já o romancista e suas técnicas de comunicação interferem de modo mediado, virtual e solitário no real, já que sua base não será um grupo de ouvintes, mas essencialmente de leitores, por isso, julgam transcender as experiências. Não é a toa que Benjamin atribuirá ao romance o papel de isolar: "Quem escuta uma história está em companhia do narrador; mesmo quem lê partilha dessa companhia. Mas o leitor de um romance é solitário" (BENJAMIN, 1992, p. 211). Daniel permite ler um local que dialoga com o universal, todavia, acrescenta a vasta tradição da oralidade ribeirinha. A este respeito o Dr. Marcio Souza ${ }^{12}$, reflete sobre o complicado debate entre Literatura Amazônica ou Literatura na Amazônia, relação que descreve em termos de falta de um público de leitores, o que dificulta o reconhecimento de autores locais. De fato, o livro Girandolas é muito pouco conhecido em nossas universidades da Amazônia, razão para o qual não se criou um corpus mais abrangente de experiência com a literatura.

A expressão literária chega a Amazônia pelo desencantamento do mundo descrito por Weber, e se tornou visível no esquecimento das tradições, o desaparecimento do narrador e o desconhecimento do autor- saber local. Sabemos que os mitos ${ }^{13}$ como narrativas fundadoras orientaram as comunidades ribeirinhas por séculos, mas só nas últimas décadas tem dado o tom as expressões literárias: exemplos são a pacoca, a cobra-grande, o boto e a

\footnotetext{
${ }^{10}$ TOLSTÓI, Liev. De quanta terra precisa um homem?. Companhia das letras, São Paulo, 2009.

${ }^{11}$ BENJAMIN, W. O narrador. Reflexões sobre a obra de Nikolai Leskov. In: Sobre Arte, Técnica Magia e Política. Trad. Maria Amélia Cruz. Lisboa: Relógio D’Água, 1992.

12 SOUZA, Marcio. Literatura Amazônica ou Literatura na Amzônia? Revista Sentidos da Cultura Belém/Pará. V.1. N. 1. Jul-dez/2014

13 ELIADE, Mircea. Mito e Realidade. São Paulo: Perspectiva, 2006.
}

MARGENS - Revista Interdisciplinar Versão Digital-ISSN: 1982-5374
10 anos de Margens - Dossiê: Olhares para o campo... VOL.10. N. 15. Dez 2016. (p. 115-132) 
Uaraci, que configuram estruturas semânticas das quais Durand (1998) qualificou de resistências do imaginário ${ }^{14}$.

Em Abaetetuba tem se manifestado uma literatura que resulta das múltiplas oralidades, apresentada ao longo de 30 anos por escritoras como Nazaré Lobato ${ }^{15}$ marco nesta caminhada. Os concursos, editais e outras inciativas acadêmicas, como IFNOPAP ${ }^{16}$ gesticulam para o horizonte de expansão da criação literária na região. A escritora Neuza Rodrigues ${ }^{17}$, por exemplo, em seu conto “Artesão de Sonhos" de 2002, narra a vida breve do artesão Cazuza, coração enamorado de Edith, sobre o qual, a trágica morte o impede de ver a festa de São Benedito. O livro "O menino que estiva o horizonte”, do poeta Lu Moraes ${ }^{18}$ (2011), relata a vivencia de personagens como (Ariramba, Açucena, Arlindo, Ventrusco e Ventoína), nas ribanceiras, canoas, açaizeiros, preamares, pescadores, peixes, crianças e um quadro de Kandisky ${ }^{19}$.

O poeta Abaetetubense Paes Loureiro ${ }^{20}$ lança em 2008, “Água da Fonte”, uma coletânea de poemas que se referem à infância em Abaetetuba. A literatura neste caso bebe na oralidade, sumo de descobertas para quem quer compreender com Oliveira (2007: p13) "Os saberes que envolvem a arte, a religiosidade, os valores e os costumes da cultura Amazônica" e que, segundo ele, devem estar no centro do debate sobre formação e pratica de educação popular nas comunidades ribeirinhas ${ }^{21}$. Bem, para tanto, "Girandolas" é um romance que é informado pelo saber local. Daniel Leite, seu autor, nasceu no Rio de Janeiro e veio para Belém ainda menino, de uma família de leitores costumava ouvir a mãe ler Dom

\footnotetext{
${ }^{14}$ DURAND, G. O imaginário: ensaios acerca das ciências e da filosofia da imagem. Rio de Janeiro: 1998.

15 LOBATO, Nazaré. Kamaig: a linguagem dos rios. Belém: IOE, 1996

16 IFNOPAP (Imaginário nas formas narrativas e orais). Vide SIMÕES, Socorro; GOLDER, Christophe (coord.). Abaetetuba Conta. Belém: CEJUP; 1995.

${ }^{17}$ RODRIGUES, Neuza. O Artesão de Sonhos. In Contistas da Amazônia: IX Concurso de contos da Região Norte. Belém: Editora Universitária, 2002.

18 MORAES, Lu. O menino que esticava o horizonte. São Paulo: Livronovo, 2011.

19 Wassily Kandisnky, pintor russo criou a obra conhecia como Primeira Aquarela Abstrata, foi também o principal teórico do abstracionismo.

${ }^{20}$ LOUREIRO, João. Água da Fonte. São Paulo: escrituras, 2008.

21 OLIVEIRA, Ivanilde; SANTOS, Tania (org). Cartografias de Saberes: representações sobre cultura amazônica em práticas de educação popular. Belém, EDUEPA, 2007. Vide também ABREU, Waldir; OLIVEIRA, Damião; SILVA, Érbio (org). Educação Ribeirinha: Saberes, vivências e formação no campo, Belém, UFPA, 2013.
}

MARGENS - Revista Interdisciplinar

Versão Digital - ISSN: 1982-5374
10 anos de Margens - Dossiê: Olhares para o campo... VOL.10. N. 15. Dez 2016. (p. 115-132) 
Casmurro de Machado de Assis. Daniel é escritor, advogado, estudante de literatura e entre outros livros e contos, escreveu também: Águas imaginárias, Casa de Farinha, Invisibilidades e outros Mundos.

Girândolas tem sua primeira edição em 2009 quando ganhou o Prêmio Samuel Wallace Mac Dowell, mas, em 2013 é reeditado pela: tempo editora e com excelentes ilustrações de Maciste Costa. O projeto do livro foi elaborado dois anos antes, com oito meses de pesquisa em campo, nas idas e vindas de Daniel a Abaetetuba, amadureceu sua poética e mergulhou no universo dos personagens, com isso, refinou o olhar. A capa do livro traz como tema o girandeiro- aquele que carrega a cruz de braças de miriti, por onde ficam suspensos os objetos estéticos- os sonhos do artesão. O professor Paes Loureiro denominou de festa do olhar $^{22}$ este gesto de fé e arte, sugerido na cor e nos temas (casal de namorados, pila-pila, cobra, ribeirinho, barcos, tatus, etc) o girandeiro empunha as braças esticadas pelos sonhos do artesão.

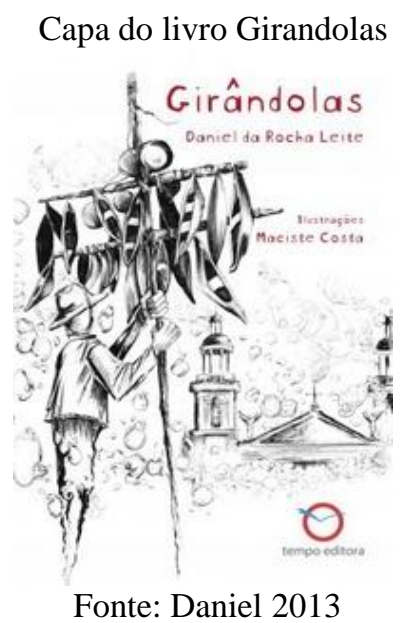

Por isso, a imagem acima é uma das resistências emergidas da cultura popular, sua dimensão ética antes que estética, expressa o uso de temas que apontam para os sentimentos partilhados numa comunidade da arte ${ }^{23}$. Embora as girândolas enquanto signo relevante para o artesão, tenha dado hoje lugar a outras estratégias de vendas do brinquedo, atrelado

\footnotetext{
${ }^{22}$ Expressão cunhada por Paes LOUREIRO, João de Jesus; OLIVEIRA, Jarbas. Da Cor do Norte. Brinquedos de Miriti. Fortaleza: Lumiar, 2012

${ }^{23}$ Vide Gomes
}

MARGENS - Revista Interdisciplinar

Versão Digital - ISSN: 1982-5374
10 anos de Margens - Dossiê: Olhares para o campo... VOL.10. N. 15. Dez 2016. (p. 115-132) 
inclusive ao design, marketing e museus, ela permanece como símbolo reconhecido no círio de Nazaré e Conceição, alcançando inclusive outras artes.

O romance é narrado na voz de Tobias numa comunidade do rio Sirituba, ele era o fazedor de brinquedos de miriti, Maria era uma benzedeira que sabia dos segredos das formigas de chuva, retratos da vida dos muitos ribeirinhos que se veem nas vozes de Tobias, Maria, velho Tibúrcio, D. Constância, D. Zefa, Dona Filomena, as crianças. O autor em entrevista ressalta que sua literatura se alimentou do mundo das pessoas, resultado de suas andanças no interior como advogado em audiências nas comunidades, e em particular, com os brinquedos de Miriti. Escrevendo percebeu que era uma história contada pela perspectiva da memória afetiva de sua infância ${ }^{24}$ : "O livro nasceu de um conto, que depois amadureceu, a partir da poética do brinquedo de miriti que me contaminou".

Para contar essa história, foi preciso: "andar pelas ruas e rios das nossas vidas que vai de Belém até Abaetetuba, ouvir as águas e ir ao encontro de suas gentes". Segundo o autor, escrever uma história pela pesquisa é contá-la a partir dos sonhos das pessoas, das suas lutas e esperanças. Além de mergulhar no universo do brinquedo ele tomou mingau no mercado, andou na feira, visitou artesões, ia aos finais de semana para ilhas, onde era recebido na casa de ribeirinhos e ouvia suas histórias, andou muito de canoa. Por isso apresentou um mundo revestido de humanidade, um encontro pela palavra que aproxima o leitor de uma Cidade dos Miritis. O poeta Paulo Viera ao tomar contato com o Livro percebe:

O autor escreveu outra história dentro de sua história. Uma história de vida pesada como os tijolos de olaria e leve como os brinquedos de miriti nas mãos das crianças. O leitor que ainda não visitou a mauritiosa cidade, ao virar das páginas desse Girândolas, vai sentir vontade de banhar-se naqueles rios. Já o leitor que alguma vez deitou nas águas do Maratauíra sentirá úmidas saudades. Agora, aquele que nasceu e cresceu em uma das pequenas ilhas sem nome de Abaetetuba, ao ler este livro, vai embarcar solidário na canoa das dores de Tobias. Vai pedir aos deuses que olhem por Maria. (VIEIRA in DANIEL 2009).

\footnotetext{
${ }^{24}$ Entrevista com Daniel Leite, autor de Girândolas, em sua residência na Rua Marquês de Herval, bairro da Pedreira, Belém-Pará, no dia 01 de Novembro de 2012, às 16h da tarde. Vide GOMES, J. Cidade da Arte: Uma poética da resistência nas margens de Abaetetuba. UFPA-Programa de Pós Graduação em Ciências Sociais, Tese de Doutorado, 2013.
}

MARGENS - Revista Interdisciplinar Versão Digital - ISSN: 1982-5374
10 anos de Margens - Dossiê: Olhares para o campo... VOL.10. N. 15. Dez 2016. (p. 115-132) 
Abaetetuba é pensada então como uma Aruanda, utopia social que se encanta na arte de um brinquedo, nas histórias dessas muitas comunidades das águas, que o autor conheceu e se envolveu. $\mathrm{O}$ autor ${ }^{25}$ envolveu-se tanto, que:

O livro me fez nascer em Abaetetuba. Eu fui à câmara de vereadores receber a medalha de honra ao mérito, depois de cidadão Abaetetubense, foi legal porque é como o Paulo Vieira diz no livro, a gente nasce onde a gente escolhe e eu escolhi nascer em Abaetetuba. Eu nasci lá, agora também, ouvindo uma história e escrevendo outra. (GOMES, 2013).

Mas, não esquece que a cidade é lugar de paradoxos, a infância referida ao brinquedo é a mesma negada na prostituição infantil, nas drogas e na violência. Por isso, reescreve uma cidade pela sensibilidade e os sonhos de seus moradores. É uma história de um amor mediado por brinquedos, uma experiência de cidade envolta pela obra de arte: Uma vida de miritis, um barco amarelo e outro vermelho, uma corrida em meio a rios e matas, o encontro com aquilo que havia sido perdido. O amor como sentimento universal ao gênero literário- Romeu e Julieta, Orfeu e Eurídice, Tristão e Isolda, o Tambataja- “amor que nunca morre”. Tobias e Maria lembram um amor em meio a barquinhos de Miriti, um porfiar das crianças das ilhas que pelo afeto realizam o estar juntos no cotidiano ribeirinho, uma escola que desperta para os primeiros encontros no meio do rio.

A esperança em seus vários dizeres

As palavras de minha mãe

O tempo de D. Constança

Uma escola no meio do rio

Sob o olhar de todos os miritizais

Guardada pelos teus açaizeiros

Uma nova história, Maria.

Uma história da gente

Uma história de gentes

Escrita por nossos próprios braços

E pelos braços sagrados de todas as pessoas que ajudam

Eu que estava prestes a te encontrar. (LEITE, 2013, p.51)

\footnotetext{
${ }^{25}$ Entrevista com Daniel Leite, autor de Girândolas, em sua residência na Rua Marquês de Herval, bairro da Pedreira, Belém-Pará, no dia 01 de Novembro de 2012, às 16h da tarde. Vide GOMES, J. Cidade da Arte: Uma poética da resistência nas margens de Abaetetuba. UFPA-Programa de Pós Graduação em Ciências Sociais, Tese de Doutorado, 2013.
}

MARGENS - Revista Interdisciplinar

Versão Digital - ISSN: 1982-5374
10 anos de Margens - Dossiê: Olhares para o campo... VOL.10. N. 15. Dez 2016. (p. 115-132) 
Este estar juntos possibilita a leitura do mundo que reacende a imagem da resistência cultural das margens e vem se apropriar de um saber partilhado pelo crivo da educação que pode ajudar a superar imediatismos e sofrimentos, tais como, a renda da terra e o escalpelamento, a falta de postos de saúde, problemas ainda visíveis entre os ribeirinhos. Acredito que apontar veredas é papel da educação e, em igual medida, o da literatura, quando atenta ao mundo presente- a vida presente: "Arrumar tudo, não vender a terra da tua família por um preço vil” (LEITE, 2013).

\section{3- Uma incursão a Escola do Campo pelo olhar de Maciste.}

Marciste esculpiu o tempo em Girandolas e apresentou-nos uma escola do campo das margens ribeirinhas, o olhar descreve uma imagem familiar para os moradores das ilhas de Abaetetuba, a escola como lugar de profunda expressão para o indivíduo cuja lembrança vai entre a dor e esperança, estruturas de sentimentos que para Willians ${ }^{26}$ criam as imagens do campo e da cidade. A imagem tem como cenário a vida "camponesa" nos rios, florestas e várzeas do Estuário do Amazonas e abrange os saberes, não a toa a escola transformou-se no totem deste romance. Tanto que os primeiros capítulos do livro tratam das memorias da infância, cenário, personagens e história, a parti do capitulo VII, temos a construção de uma escola, a vinda de uma professora, a leitura do primeiro livro e uma busca da ciência do viver.

Vejamos como ficaram impressionante os traços que lembram o grafite, e que ganham uma natureza real pelo tema tratado e os sonhos presentes.

${ }^{26}$ WILliANS, Raymon. Campo e Cidade: Na história e na literatura. São Paulo, Companhia das letras, 2011

MARGENS - Revista Interdisciplinar

Versão Digital - ISSN: 1982-5374
10 anos de Margens - Dossiê: Olhares para o campo... VOL.10. N. 15. Dez 2016. (p. 115-132) 
Ilustração de uma escola do campo

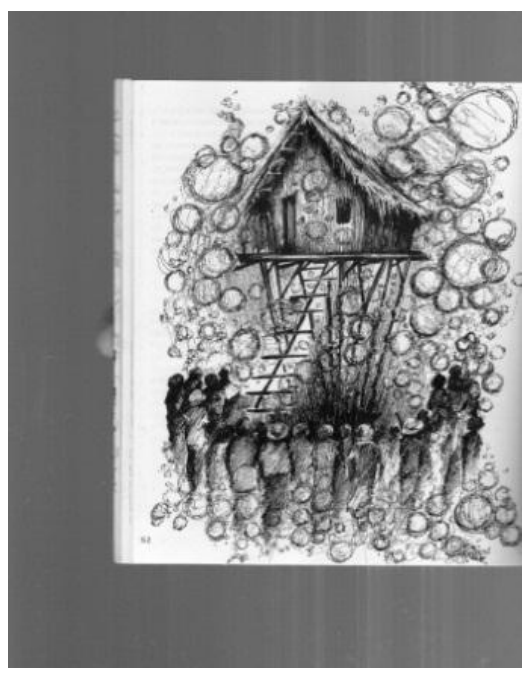

Fonte: livro Girândolas

A ilustração vem, portanto, redesenhar o romance a partir deste momento histórico tão esperado nas comunidades, com isso registra um fenômeno decisivo para as gerações de ribeirinhos. Maciste cuidou para que os elementos básicos não faltassem na imagem de uma escola do campo: o mutirão, a elevação e o sonho, são algumas das questões arroladas pela aparição deste fenômeno em meio a vida ribeirinha. O tema trabalho das mãos quer responder as necessidades cotidianas que os ribeirinhos enfrentam, a pesca de mapara, o fazer do matapi, a roça, a farinha, assim, construir uma escola é um gesto exemplar do trabalho social.

Um sonho: Uma escola que ensinasse a vida e todas as ciências do viver. Um todo alfabeto, um início, o soletrado das águas de um rio. Vieram, então os braços de muitas pessoas para afirmar esse sonho verdade, de todos os cantos das águas surgiram pessoas dispostas a ajudar a construir esse tempo" (LEITE, 2013:p.53)

O segundo nasce da imagem do lugar elevado acima das águas, no limiar de um trapiche sinal da cultura nas margens. O elevar-se, educar-se, aprender, é um dos elementos sugeridos pelo termo latino ecole- lugar do pensamento e da reflexão- possiblidade de rompimento com a percepção do "campo" como lugar do atraso. A possibilidade do conhecimento das palavras e do seu consequente uso, é a marca da escola como processo histórico consciente e fundamento da liberdade.

MARGENS - Revista Interdisciplinar Versão Digital - ISSN: 1982-5374
10 anos de Margens - Dossiê: Olhares para o campo... VOL.10. N. 15. Dez 2016. (p. 115-132) 
Dona Constança nos alfabetizou em dois anos. Com o seu trabalho e as luzes que semeou em nossos olhos alinhavou as nossas vidas. Alguém improvisou um quadro-negro, à guisa de lousa, com uma tinta escura na massa polida do barro na parede. Quando os olhos se iluminaram estava pronto o destino: uma sala de aula. Um lugar para se conquistar uma liberdade. Idem

O ato da reflexão aponta para a tarefa de reconhecer um "estar junto" no diálogo entre o local e o global, entre natureza e a cultura. Os fragmentos temáticos presentes em Girândolas dizem muito da "leitura" como prática de conquista de uma liberdade. O livro que Tobias ganhou da professora D. Constança, o "Marajó" de Dalcídio Jurandir, levara-lhe a ler as boas histórias, descobrir outros mundos, reconhecer seu próprio mundo, como um lugar diferente do que estava acostumado a olhar. Por fim o elemento onírico representado nas bolhas que saem das cabeças das pessoas e que estão ao redor da escola, acaba sendo uma projeção de todas as possibilidades trazidas com a imagem utópica, um anseio e uma ideia: "um espaço para nossa voz, um taipamento feito por todas as mãos. Um além de uma casa, a nossa escola, um inaugurar de uma nova história" (LEITE 2013:69).

\section{4- Narradores da maré: Travessias de um reconhecimento}

Em viagem de realização do tempo-comunidade da Turma de licenciatura em Educação do Campo 2014/UFPA- Abaetetuba, na Escola São João Batista, anexo da Escola Estadual de Ensino Fundamental e Médio Pedro Teixeira, localizada no rio Campopema no Barracão de São Benedito, exatamente no dia 22 de fevereiro de 2016, pude observar o quanto a escola do campo se faz carente de estrutura e pessoal, capaz de propiciar um ensino mais inclusivo e diferenciado. Desde o encontro com os alunos na feira da cidade de Abaetetuba ao deslocamento do barco a ilha do Campopema, que se deu por volta das 08:30 da manhã pude me colocar na condição de travessia a que muitos ribeirinhos se submetem todos os dias no afã das mais diversas atividades, (educativas, comerciais, etc), neste percurso não poderiam passar despercebido o emaranhado das águas e as gentes paisagem naturais que pelo olhar despretensioso cambem toda uma estética.

MARGENS - Revista Interdisciplinar Versão Digital - ISSN: 1982-5374
10 anos de Margens - Dossiê: Olhares para o campo... VOL.10. N. 15. Dez 2016. (p. 115-132) 
Entre o rio e a margem de onde atracamos a vista do trapiche, o barracão da comunidade e a igreja, fiquei pensando no tema de nossa pesquisa ${ }^{27}$ e de como iria coordenar os trabalhos. Logo após a divisão de tarefas nos grupos preestabelecidos e orientados no tempo-universidade passamos a observar os desafios da educação nas ilhas. No intervalo pro almoço me debrucei num diálogo com uma discente do curso moradora do referido rio, que lembra "a dificuldade que teve em concluir o ensino fundamental e médio, quando precisava ir a cidade diariamente de canoa, passava necessidades.

A tarde nos deslocamos para a escola que possuía a estrutura de um barracão ${ }^{28}$ e exibia instalações precárias de funcionamento, além de carência de suportes pedagógicos e de pessoal de apoio, fatos que somavam-se ao calor, barulho, baixa luminosidade. Ora, a permanência do professor na escola era um ato de resistência, ou seja, ficava a sua própria sorte, o que parecia contingenciar uma ação pedagógica eficaz. Vejamos os relatórios de pesquisa das alunas Marinete Paixão e Maria Monteiro:

É importante destacarmos que a estrutura da escola é bastante precária causando desconforto tanto para os professores quanto para os alunos influenciando bastante no ensino aprendizagem, os alunos estudam num barracão e as sala de aula são divididas em compensados, o calor e o barulho são alguns dos fatores bem relevantes que acabam dificultando $o$ entendimento do aluno.

O capítulo VII do livro traz a imagem da escola nas ilhas, que construída com o trabalho das mãos dos moradores e mantida a despeito das adversidades, permite os laços sociais: "Todas as gentes que moravam ao longo das sete comunidades, ajudaram no trabalho de levantar a escola no meio de nossas águas” (LEITE 2013). Neste misto de dor e esperança torna-se público um problema quase sempre em devir, educar! Ora, não é fato novo que os moradores das ilhas e estrada valorizam a presença de um professor, de uma escola, por mais humilde que seja.

27 O tema gerador do tempo comunidade na visita foi definido em: "Escola do Campo, Ensino Médio e Interdisciplinaridade", com o objetivo de focalizar níveis de ensino e práticas pedagógicas.

${ }^{28}$ A referida escola é um anexo da Escola Estadual de Ensino Médio e Fundamental Pedro Teixeira-sede do Município de Abaetetuba.

MARGENS - Revista Interdisciplinar Versão Digital - ISSN: 1982-5374
10 anos de Margens - Dossiê: Olhares para o campo... VOL.10. N. 15. Dez 2016. (p. 115-132) 
Isto fica expresso na fala da discente do curso que parece lembrar pela passagem do livro esta cena: "Quando li o livro lembrei-me quando estudava e não tinha escola, estudávamos no barracão da comunidade onde as salas eram divididas por folhas de compensado. Quando houve o boato de que ali na nossa localidade iria ser construída uma escola, toda comunidade ficou contente e se reuniram para ajudar na construção". Outro aspecto narrado no livro e que encontra seus ecos nas falas dos alunos, diz respeito a presença do professor, como: "Dona Constança que na comunidade marcou os percursos dos alunos de um rio", estes mediaram seus encontros sobre a presença cuidadosa dela, que, por sua vez, apontou o relato de uma aluna do Murutinga: "Mas quando se tem a graça de ter uma professoram como D. Constança que valorize o que você é e o que você tem, conhecimentos, saberes, você passa a se valorizar também”.

A educação para estes alunos se faz importante, porque compreendem suas expectativas em relação a continuidade dos estudos e a despeito das grandes dificuldades no ensino básico, o sonho desses alunos terem chegado a uma universidade concretiza-se de forma a colocar novamente novos desafios na busca de formação, qualificação, e sobretudo, de um olhar mais cuidadoso e reflexivo sobre si mesmo e sua cultura. Tal como o indicado nas diretrizes operacionais para a Educação do Campo ${ }^{29}$.

A identidade da escola do campo é definida pelas questões inerentes a sua realidade, ancorando-se na sua temporalidade e saberes próprios dos estudantes, na memória coletiva que sinaliza futuros, na rede de ciência e tecnologia disponível na sociedade e nos movimentos sociais em defesa de projetos que associam as soluções por estas questões a qualidade de vida coletiva no pais (MEC,2002,P.37).

A Educação do campo que nos seus níveis (Básico e Superior), somente nas últimas décadas tem alcançado o patamar de políticas públicas com expressões locais na interiorização da Universidade e Sistemas Modulares de Ensino e a atuação dos movimentos sociais no histórico direito a uma educação do campo. $\mathrm{O}$ campo não se restringe ao espaço de produção de alimentos para a cidade, mas um lugar de vida cultural cuja totalidade cria

29 MEC Resolução CNE/CNB, n 1. Diretrizes operacionais para a educação básica para as escolas do Campo, Brasília, Distrito Federal, 2002.

MARGENS - Revista Interdisciplinar Versão Digital - ISSN: 1982-5374
10 anos de Margens - Dossiê: Olhares para o campo... VOL.10. N. 15. Dez 2016. (p. 115-132) 
uma simbiose que regula a diversidade socioambiental nas comunidades da Amazônia- a produzir suas artes de fazer e todo um conjunto significativo de signos que desafiam o pensamento complexo a recolocar a questão do local-global pelo olhar em perspectiva das margens ribeirinhas.

\section{5- Conclusão:}

O objetivo deste estudo foi intermediar um diálogo entre literatura e educação. Cabe ressaltar que a escola do campo nas margens ribeirinhas do baixo Tocantins tem suscitado um reconhecido debate nos movimentos sociais de onde tiveram origem e hoje na universidade por onde passa a ser problematizada, vivenciada e amadurecida. Demonstramos que a escola do campo se faz presente nos temas levantados no livro Girândolas do escritor Daniel Leite, tanto que o autor dedica uma parte significativa de três capítulos no afã de perceber um tema sociológico em meio ao pedagógico e estético em meio ao ético. Quando passamos a escutar os alunos de licenciatura em educação do campo e as imagens de Maciste se revelavam na fronteira de tudo que sabemos e não sabemos sobre o ensino no campo, passamos a ver a escola na dupla dimensão: dor e esperança. As narrativas alcançam estes fatos e para além deles mergulham nos encantos e desencantos da região, e uma vez mais, somos convidados a como Dalcídio Jurandir, olhar para os Campos de Cachoeira, de onde ilhas e rios ditam as lições das margens- vazantes e enchentesprelúdios de uma vida ribeirinha.

\section{6- Referencias:}

ABREU, Waldir; OLIVEIRA, Damião; SILVA, Érbio (org). Educação Ribeirinha: Saberes, vivências e formação no campo, Belém, UFPA, 2013.

BENJAMIN, W. O narrador. Reflexões sobre a obra de Nikolai Leskov. In: Arte, Técnica, Magia e Política. Lisboa: Relógio D’Água, 1992.

BOSI, Alfredo. Literatura e Resistência. São Paulo: Companhia das letras, 2002. CERTEAU, M. A invenção do Cotidiano: Artes de fazer. Petrópolis: Vozes, 2003.

MARGENS - Revista Interdisciplinar Versão Digital - ISSN: 1982-5374
10 anos de Margens - Dossiê: Olhares para o campo... VOL.10. N. 15. Dez 2016. (p. 115-132) 
MEC Resolução CNE/CNB, n 1. Diretrizes operacionais para a educação básica para as escolas do Campo, Brasília, Distrito Federal, 2002.

ELIADE, Mircea. Mito e Realidade. São Paulo: Perspectiva, 2006.

DURAND, G. 0 imaginário: ensaios acerca das ciências e da filosofia da imagem. Rio de Janeiro: [s. n.] 1998.

RICOEUR, Paul. Percurso do Reconhecimento. São Paulo: Edições Loyola, 2006.

RODRIGUES, Neuza. O Artesão de Sonhos. In Contistas da Amazônia: IX Concurso de contos da Região Norte. Belém: Editora Universitária, 2002.

LOUREIRO, João de Jesus; OLIVEIRA, Jarbas. Da Cor do Norte. Brinquedos de Miriti. Fortaleza: Lumiar, 2012. Água da Fonte. São Paulo: escrituras, 2008.

LOBATO, Nazaré. Kamaig: a linguagem dos rios. Belém: IOE, 1996.

LEITE, Daniel. Girândolas. Belém, 2a Edição: tempo Editora, 2013.

MORAES, Lu. O menino que esticava o horizonte. São Paulo: Livronovo, 2011.

TOCANTINS. Leandro. O rio comanda a vida. Rio de janeiro: José Olímpio, 1983.

SOUZA, Marcio. Literatura Amazônica ou Literatura na Amzônia? Revista Sentidos da Cultura Belém/Pará. V.1. N. 1. Jul-dez/2014.

JURANDIR, Dalcídio. Marajó. Belém: UFPA, 2008.

MARGENS - Revista Interdisciplinar

Versão Digital - ISSN: 1982-5374
10 anos de Margens - Dossiê: Olhares para o campo... VOL.10. N. 15. Dez 2016. (p. 115-132) 
GOMES, J. Cidade da Arte: Uma poética da resistência nas margens de Abaetetuba. UFPA-Programa de Pós Graduação em Ciências Sociais, Tese de Doutorado, 2013.

ROSA, Guimarães. Grandes Sertões: Veredas. Rio de Janeiro, Nova Fronteira, 2006.

MORAES, Lu. O menino que esticava o horizonte. São Paulo: Livronovo, 2011.

TOLSTÓI, Liev. De quanta terra precisa um homem? Com das letras, S. Paulo, 2009.

WILLIANS, R. Campo e Cidade: Na história e na literatura. São Paulo, C. letras, 2011.

SIMÕES, Socorro; GOLDER, Christopher. Abaetetuba Conta. Belém: CEJUP; 1995.

OLIVEIRA, Ivanilde; SANTOS, Tania (org). Cartografias de Saberes: representações sobre cultura amazônica em práticas de educação popular. Belém, EDUEPA, 2007.

MARGENS - Revista Interdisciplinar

Versão Digital - ISSN: 1982-5374
10 anos de Margens - Dossiê: Olhares para o campo... VOL.10. N. 15. Dez 2016. (p. 115-132) 